\title{
Numerical Simulation Applied to PVD Reactors:
} An Overview

\author{
Gustavo Pinto ${ }^{1,2, * \mathbb{D}}$, Francisco Silva ${ }^{2}{ }^{\mathbb{D}}$, Jacobo Porteiro ${ }^{1}$, José Míguez ${ }^{1}$ \\ and Andresa Baptista 1,2 \\ 1 UVIGO-School of Industrial Engineering, University of Vigo, Lagoas-Marcosende, \\ 36310 Vigo-Pontevedra, Spain; porteiro@uvigo.es (J.P.); jmiguez@uvigo.es (J.M.); absa@isep.ipp.pt (A.B.) \\ 2 ISEP—School of Engineering, Polytechnic of Porto, 4200-072 Porto, Portugal; fgs@isep.ipp.pt \\ * Correspondence: gflp@isep.ipp.pt; Tel.: +351-228-340-500
}

Received: 16 September 2018; Accepted: 16 November 2018; Published: 19 November 2018

\begin{abstract}
The technological evolution in the last century also required an evolution of materials and coatings. Therefore, it was necessary to make mechanical components subject to heavy wear more reliable, improving their mechanical strength and durability. Surfaces can contribute decisively to extending the lifespan of mechanical components. Chemical vapor deposition (CVD) and physical vapor deposition (PVD) technologies have emerged to meet the new requirements that have enabled a remarkable improvement in the morphology, composition and structure of films as well as an improved adhesion to the substrate allowing a greater number of diversified applications. Thin films deposition using PVD coatings has been contributing to tribological improvement, protecting their surfaces from wear and corrosion, as well as enhancing their appearance. This process can be an advantage over other processes due to their excellent properties and environmental friendly behavior, which gives rise to a large number of studies in mathematical modelling and numerical simulation, like finite element method (FEM) and computational fluid dynamics (CFD). This review intends to contribute to a better PVD process knowledge, in the fluids and heat area, using CFD simulation methods focusing on the process energy efficiency improvement regarding the industrial context with the sputtering technique.
\end{abstract}

Keywords: CFD simulation; FEM simulation; reactor; physical vapor deposition; coating; numerical modelling

\section{Introduction}

In the last century and at the beginning of this century, technology had a great evolution. Associated with this evolution, was a great and strongly positive progress in terms of resistance to wear, corrosion, adhesion, appearance, chemical stability, more efficient behaviors to increase the surfaces' lifetime, amongst others.

This technological evolution is essentially promoted by a set of characteristics and parameters, not just due to a single one. This progress accelerated the development of new studies, namely, research studies in Surfaces and Mechanical Engineering [1-3]. Due to the technological advance in the coatings field, it was possible to improve the surfaces' behavior, namely physical and mechanical properties. It is possible to improve surface wear resistance, surface look, chemical stability, fatigue behavior, adhesion to the substrate, protecting the substrates against abrasion, erosion and corrosion, decreasing friction coefficients and residual stresses [4-13]. The need to respond to the new demands aroused the interest of a huge number of researchers. The evolution of the ultra-thin hard film deposition technique has allowed the improvement of surface characteristics and properties [14,15]. Due to the strong importance of these characteristics, many studies have been done in the field of mathematical modeling and numerical 
simulation of coatings. One of the most influent characteristics in the performance of the coatings' mechanical properties is the thermal conductivity of the substrates and, for this reason, has been also deeply studied in the last decade [16]. In these works, the correct data treatment is important as well as the thermal and mechanical analysis and the interpretation of the simulation results [17]. The recent known structure of FEM is based on studies and developments made around the 1940s [18-20]. The first research work developed using FEM was carried out based on aero-structures in the late 1950s [18,21]. In the mid-1960s researchers launched their first works in thermal analysis and fluid flow [18,22,23]. In the 1930s, scientists and researchers began using the Navier-Stokes equations to study fluid flows. Due to the lack of computational capacity, these equations were simplified and reduced to two dimensions to be manually calculated. After the beginning of the computational development, from the 1950s to nowadays, CFD was used to characterize and solve problems in the fluids area. In 1957, the first 3D model of CFD simulation was developed. This project was completed 10 years after its beginning. NASA and Boeing were the driving force behind the application of CFD simulation. Euler's equations were applied to the CFD in the 1980s. In the 1990s, the automotive industry looked at this simulation method as an added value, starting to use it. By this way, the aerodynamics of vehicles like GM and Ford was deeply improved based on CFD studies. Currently, the simulation to characterize and solve problems using CFD is widely used due to the existence of a greater number of researchers involved in this issue, as well as due to the existence of more powerful computers [24-33].

Some studies, such as to predict the velocity, pressure, and density profiles; concentration and distribution of the process gas species; plasma improvement by optimizing the vacuum system; design and modelling of the anodic chamber reactor; collisions process between target and substrate; effect of the turbulence in biomass combustion; vapors' behavior from materials and gases deposition, were also performed using the computational fluid dynamics (CFD) numerical simulation [29,30,34-36]. The simulation tool is widely used to study and fix real problems [37], and thus, avoiding the cost of equipment stoppages [38]. However, these tools need powerful computers to solve, for instance, a combustion systems problem, because the mesh and the equations number are critical [39].

The following sections will mention research works with FEM simulation, namely, the study of mechanical properties, defects and deformation material, wear and tribological performance of tools, contact between the coated PVD tool and the workpiece, PVD coating thermomechanical properties, coating fracture surface and CFD simulation, namely, process gas species into the sputtering chamber, temperature, pressure and velocity distribution optimization, fluid flow dynamics, thermal evaluation in a reactor design, evaluate, predict, improve and/or optimize processes like in biomass combustion [34,38-41], in fuel combustion [42], in different conditions and reactors types, such as solar tubular, a continuous Photo Fuel Cell (PFC), tubular Pd-Ag membrane, industrial Claus and industrial PVD reactors, among others [24-33]. These challenges motivated researchers to improve performance of coatings, giving rise to several variants of coatings techniques.

The FEM and CFD simulations help to understand the behavior of the PVD coating process, as well as the reactor used. In this work, it will be studied and dissected several works using FEM and CFD simulation. These studies have a high relevance from the moment that their physical reproduction becomes very expensive. With simulation, a good approach is possible, reducing costs and time spent. With the creation of mathematical models in 2D and 3D simulation, it is possible to cover a huge number of practical cases. The knowledge acquired about the problems and their formulation and characterization allows to better understand the real characteristics of the problem. In the end, an implementation and validation through a real-scale test must be done, making the model truly dependable $[26,27,29]$. The simulation used in many mathematical models to study the tribological material characteristics serves to improve the surfaces' protection, and thus, to be more resistant to wear and corrosion phenomena. They also can improve the structure and composition of films, as well as optimize the process variables of PVD coatings [31]. 
This research focus on the numerical simulation works using FEM and CFD applied to PVD coating processes. In this review, it will be made a small introduction to the PVD process to realize the usefulness on 2D and 3D simulation, namely, FEM and CFD simulation techniques.

\section{Physical Vapor Deposition Technique}

To provide solutions to problems associated with the characteristics of metallic and non-metallic materials, such as corrosion protection, wear resistance, high-temperature resistance, reduction of friction, adhesion, among others, the PVD coating process brought some response to solving them $[1,43-47]$. One technology that greatly benefited by this deposition technique is the cutting tools or machining tools $[45,48-50]$. With this technological evolution, other industries benefit by reducing maintenance costs, improving productivity and remaining economically competitive [51]. With PVD coating, it is possible to decrease friction and improve thermal properties $[3,15,52-54]$. The material technology evolution has brought some variants to conventional coating techniques, such as, High-Power Impulse/Pulse Magnetron-HiPIMS/HPPMS [43,55-57]. In the next two Figures 1 and 2, it is possible to see the commonly used coating techniques, namely the gaseous state processes like the chemical vapor deposition (CVD) and PVD [58-60].

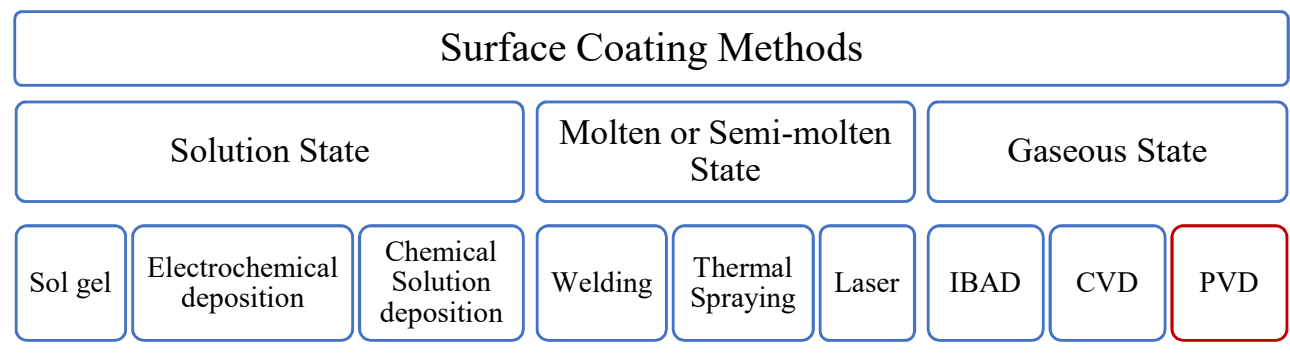

Figure 1. Surface coating methods.

\begin{tabular}{|c|c|c|c|c|c|c|c|c|c|}
\hline \multicolumn{10}{|c|}{ PVD } \\
\hline \multicolumn{4}{|c|}{ Evaporative } & \multicolumn{6}{|c|}{ Sputtering } \\
\hline $\begin{array}{l}\text { Electron } \\
\text { Beam Gun }\end{array}$ & Indutive & Resistive & Arc & Triode & $\begin{array}{c}\text { Ion } \\
\text { Beam }\end{array}$ & Magnetron & Diode & RF & $\begin{array}{l}\text { Pulsed } \\
\text { Plasma }\end{array}$ \\
\hline
\end{tabular}

Figure 2. Physical vapor deposition (PVD) coating methods.

In the surface treatment processes, a vapor phase environment is created before modifying or depositing on the surfaces. As can be seen in Figure 2, Sputtering PVD is a coating technique such as evaporation PVD however, targets are used which are bombarded by an inert gas to release nearly atomic particles to be deposited on the substrates and thus create the coating [58-60]. As in the Sputtering process, the process of PVD evaporation uses high vacuum pressure. However, the PVD Evaporation utilizes low atomic energy. This process is characterized by allowing the production of thicker films and presenting lower adhesion to the substrate because the coating absorbs less energy during the process and the mass particles are larger compared to sputtering. It should be noted that this process is widely used in an industrial context where the coating morphology is not the main requirement [60-63].

In PVD deposition, a material is projected through one or more solid sources, called Targets. This projection reaches one or more substrates in a steam plasma environment in a vacuum chamber, as can be seen in Figure 3 [61]. In the PVD process, the vacuum plasma aims of forming a thin film on the surfaces to produce one of the above-mentioned effects. For the coating process to be effective, it is necessary to take into account certain parameters, such as the coating material, the temperature, the gas, among others. In the case of the material, it is important to choose the most appropriate because it will interfere with the adhesion to the substrate [62]. 
Vacuum Chamber

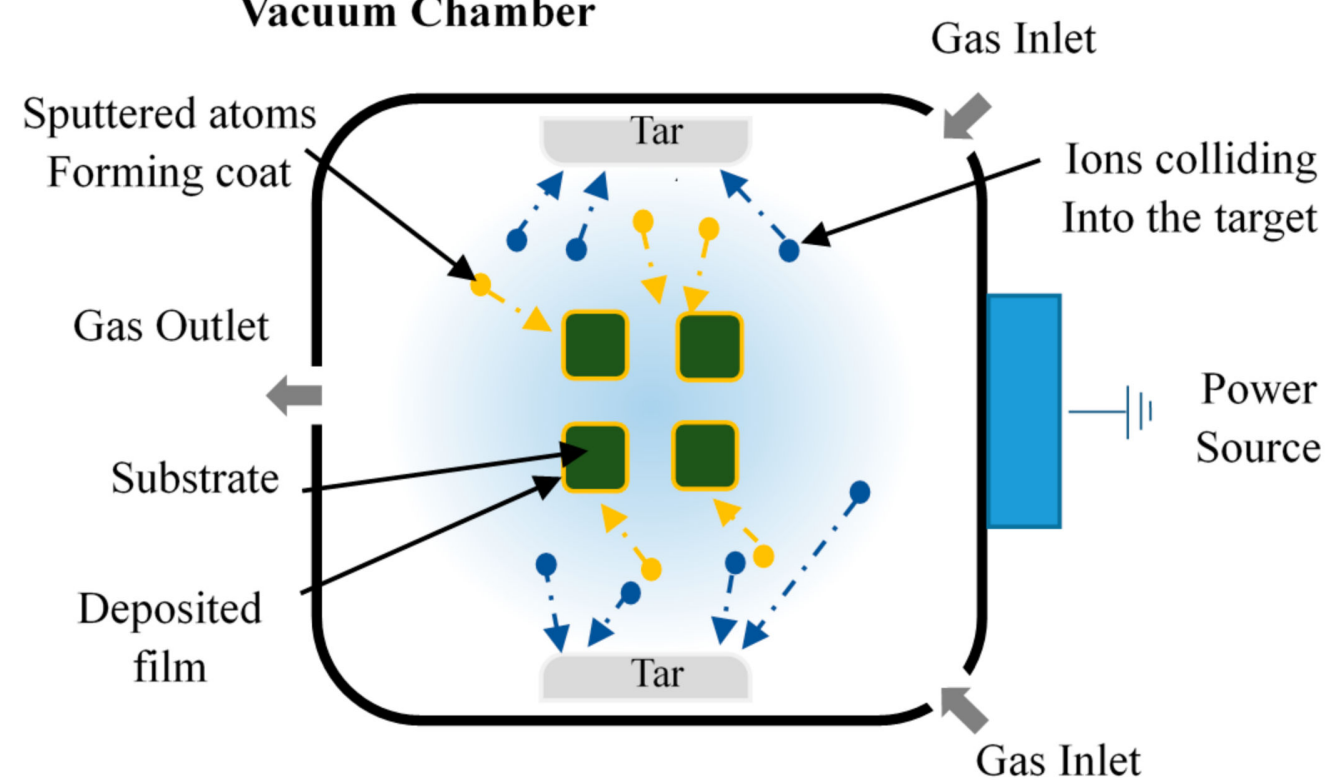

Figure 3. PVD deposition.

\section{Evolution Regarding the Methods to Solve Engineering Problems}

In the middle of the last century, computer technology had begun to have a tremendous revolution, and this made a global technological evolution, namely the technologies that depend directly and indirectly on computers [64]. Since then, complex engineering work has been solved using computers with advanced software [65]. In Figure 4, a summary of the methods to solve problems and observed differences can be seen. For instance, in the analytical methods, the calculation is done through a classical approach. The obtained results present high accuracy, although the analyzed problems have low complexity degree. The experimental method is based on the physical prototypes. It has the disadvantage compared to other methods in preparation time as well as cost. For results to be reliable, usually three or five samples are required. Numerical methods are a mathematical tool designed to simulate and solve mathematical processes of real-world problems [66]. These are techniques that use arithmetic operations to solve engineering problems [67]. The results are usually validated by other methods, such as, experimental or analytical. When the simulation is used to study a real-world problem, it is expected that the characterization is as close as possible. This approach is one of the parameters that influence the study success. Consequently, powerful computers are necessary, a great knowledge of the tool used, as well as a great knowledge on how to solve the problem. In these studies, no prototypes nor physical tests are necessary in order to cause stopping the machine, avoiding additional costs. Once the mathematical model is created, it is possible to improve or optimize the problem quickly, regardless of the complexity degree.

The computational simulations, namely FEM and CFD, used to understand, optimize or solve problems are mathematical approaches to a real study environment, with a friendly graphical environment [68]. It is generally known that there are restrictions regarding the use of simulation tools, such as the investment in the software, the knowledge needed to work with it and to control the subject, however, the simulation has helped and will help to solve a lot of complexes problems that otherwise would be impossible to solve. Working on a research project in PVD coating requires a broad knowledge, e.g., Computer Science, Mathematics, Fluid Mechanics, Materials Mechanics, Chemistry, among others. Figure 5 shows an example referring to the multiple areas of knowledge for a PVD coating simulation project. 


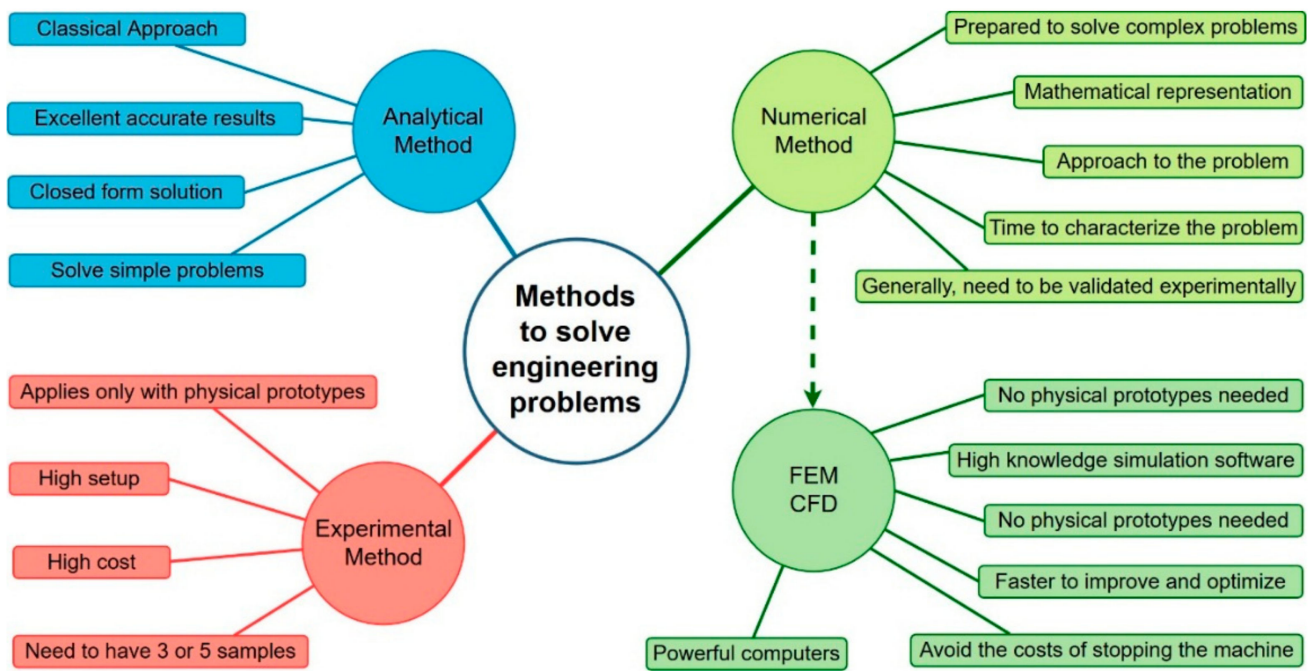

Figure 4. The evolution of different methods to solve engineering problems. FEM: finite element method; CFD: computational fluid dynamics.

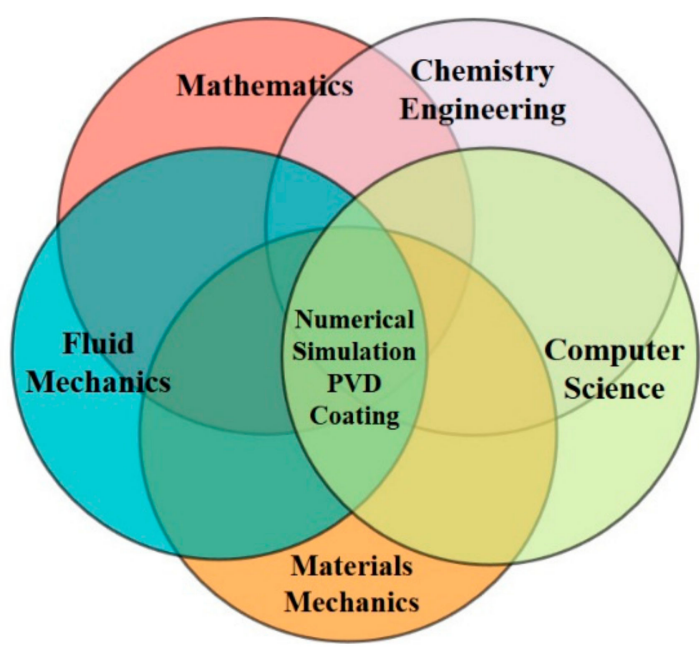

Figure 5. Multidisciplinary nature of numerical simulation methods.

The evolution of computing technology allows its use even without having a higher programming skill. Initially, the simulation method had, as its strongest point, the ability to solve complex problems, now also has the ability to make the data available in a way that allows export to be worked later. The communication has been improved because the graphics output capabilities have also been improved. So that, to show the ideas to non-specialists became easier [69]. In Table 1, it is possible to see the focus of studies with numerical methods and PVD reactors [70].

In the following sections, the numerical simulation methods, namely the FEM and the CFD will be presented.

Table 1. Numerical simulation methods and their focus: CFD and FEM.

\begin{tabular}{cc}
\hline Numerical Simulation & Analysis/Study \\
\hline CFD & Based on the reactor's process \\
FEM & Based on the product and its characteristics \\
\hline
\end{tabular}




\section{Finite Element Method (FEM)}

Simulation software helps solve really complex problems in the areas of aeronautics, nuclear and space travel, where safety and reliability requirements are the main concerns. Other works, also of high complexity, such as chemical pollution control, acoustic and thermal, are studied to improve their performances. Simulation is not synonymous of success, it is necessary to create mathematical models. Sometimes, it is necessary to be selective in the parameters to use because too much information can mean failure [71].

In the last decades, there has been a marked increase in the use of simulation software, namely, based on FEM. This type of software has made a great contribution to the modelling of complex problems [72]. In fact, mechanical engineers use numerical method tools to study and solve real problems. Researchers use the FEM because it is prepared for the areas of aerodynamics, heat transfer, mass transport and electromagnetic potential, stress analysis and others [73,74]. FEM, in order to achieve an approximate solution, needs a discretization of the volumes, creating a mesh adequate to the accuracy and detail requirements imposed by each problem. The result is only an approximation and not the real solution. Even so, there is always the risk that mathematical tools will not be able to come up with an exact or even an approximate solution. After arriving at an approximate solution, it is possible to work and make closer to the real solution, requiring greater computational effort [75].

The FEM has three distinct phases. In the first one, the real problem to be studied is characterized, to create the mathematical model and then arrive at a numerical solution. The second and third phases will be closer to the real solution the closer the characterization is to the actual problem. For the study success, it is necessary to use the appropriate equations according to the work. The finite element mesh must be thin to have higher resolution, but if it is overly thin, the processor may not have the working ability to perform the computation. In the analysis phase, the software solves a system of equations taking into account the data acquired, as well as the conditions introduced previously. In the third and final phase, the results provided by the computer are interpreted. Here, the researcher's experience with the problem and the software has a great influence [76]. In this section, it can be seen some works with a high degree of complexity:

- Śliwa et al. [7] studied the difference and the stress distribution between the coating and the substrate. The stress studied is distributed in the multilayers taking into account the deposition technique used in the magnesium substrate. The values obtained in the simulation were validated with experimental values. The conclusion was clear, the FEM can be useful in predicting the coating properties in surface engineering. After validation of the model, it is possible to reduce the tests in the laboratory, reducing the time and the cost. In the study, it can be concluded that it is possible to discover the solidified pores and droplets as well as the depressions caused by ejected droplets of the deposited PVD material.

- Śliwa et al. [17] made another study on the internal stresses in the PVD-magnetron coating with different temperatures, between $460{ }^{\circ} \mathrm{C}$ and $540{ }^{\circ} \mathrm{C}$. The characteristics of the material used in the simulation were high-speed sintered ASP 30 steel. The simulation was performed in ANSYS ${ }^{\circledR}$ software. The validation of the simulation results was done through experimental tests. The results obtained in the simulation and in the experimental tests converged, thus validating the created FEM model. The study shows, through the validation of the results, that the FEM model created is able to characterize the stresses caused by deposition of the PVD coating.

- Skordaris et al. [4] investigated TiAlN PVD coatings, namely cemented carbide residual stresses. In the work was used nano-impact test, nanoindentations and FEM to study the mechanical properties, fragility, adhesion and cohesion. The conclusion shows that the wear of the coated tools increases if the residual stresses are higher than the maximum allowed value although, some compression stresses on the film contribute to increasing the mechanical properties of the coating and consequently a longer useful life. 
- Skordaris et al. [77] created a FEM model to study and simulate the surface fracture of the coating in nano-impact tests. The creation of the model will serve to study the behavior of this type of tests. The model created will allow the simulation for single and multilayers. After validation of the model, it is possible to be applied for brittleness structures studies of coatings.

- Skordaris et al. [78] studied the influence of the coating thickness on the tools through FEM simulation. This study verified whether HPPMS (high power pulsed magnetron sputtering) PVD coatings can be used more efficiently in cutting processes. The multilayer PVD deposition instead of mono-layer on cemented carbide tools help them to increase useful life due to their capability to prevent the crack propagation. The study showed that the useful life of the carbide tool significantly improves if the deposition is done in multilayer PVD. The FEM simulation on the contact of the coated tool and the workpiece shows that the thickness of the coating film has an influence on the wear, that is, the useful life of the tool increases proportionally with the increase of the film thickness. Thus, the increased cost of the coating is offset by the enlarged useful life of the workpiece.

- In PVD coatings, the nano-impact test is widely used to check the failure mechanisms of the film. A disadvantage of these tests is the introduction of local deformations and stresses in the film. To replace these tests, Bouzakis et al. [79] developed a model in FEM. Thus, the model can simulate the nano-impact test on a TiAIN PVD coating. In this simulation, the real conditions were used. To validate the model, it was compared the simulation results with the real ones. The results of the developed FEM model converge with the experimental results. The model predicts the film failure initiation and evolution and can be used with various strength properties and surface treatments.

- Micro-blasting in PVD films can cause material deformation, modifying the surface mechanical properties of PVD films. For this reason, Bouzakis et al. [9] developed a FEM model to predict residual stresses after micro-blasting. The model was validated after analysis of the experimental data and the results obtained in the simulation.

- Wang et al. [80] studied thermal insulation and fracture failure problems of thermal barrier coatings (TBCs) using FEM. After creation and validation of the FEM model, it is possible to predict the effect of the interfacial thermal resistance, the residual stress between the coating and the substrate, the convection between the environment and the coating or the residual stress that is induced by the plasma.

- Wang et al. [81] used the FEM to model and study the thermal barrier coating (TBCs), namely the heat transfer behavior. The study was based on different models of interfacial thermal resistance (ITR) with different conditions. The heat flow around the interface presents very interesting changes in the characteristics. The thermal conductivity of as-spray TBCs is influenced by the roughness of the interface. In this investigation, a useful guide was created to design coatings in the future.

- Beblein et al. [82], created a FEM-2D model to study thermomechanical properties of coatings devoted to cutting tools. For the model fits as close as possible to the real problem, the coating properties were used, such as the physical and technological limits of CrAlN. They concluded that the thermodynamic load at the cut is influenced by the adhesion behavior and the thickness of the coating. The stresses in the coating are influenced by Young's modulus, but the stresses within the substrate are not affected. The increase in the thickness of the coating causes a build-up of heat because it has low thermal conductivity.

- Bolot et al. [83] used the FEM to study, the coating macro-properties and its microstructure. With this study, they are able to predict the defects and the voids that cause a decrease of the thermal conductivity. Therefore, the study focused on the thermomechanical properties of a coating composed of powdered plasma.

- Rao [10] created a FEM model to evaluate the mechanical properties of thin films, particularly in Nylon coatings deposited on soda-lime glass substrates. Hardness and Young's modulus were 
extracted by experimental results. To validate the model, experimental data were compared to the simulation results. It can be said that the model is close to the real problem after results analysis.

- Lofaj et al. [84] studied the influence of the indentor tip radius on the penetration in coatings with the FEM help. In this study, nanoindentation and its depth profile module with different radii were also used in hard steel substrates for coating tungsten carbide. It was concluded that it is necessary to be careful with the false results. This will occur if the radius of the tip of the indenter increases or the thickness of the coating decreases. Under these conditions, a reduction of the peak of the depth profiles will take place.

- Paiva et al. [16] studied the wear and tribological performance of $\mathrm{TiB}_{2}$ coatings used on cutting tools under different machining conditions. The FEM simulation was done to model the problem and thus study the friction surface. The study focused on the temperature profile for machining conditions with different parameters. SEM, EDX and XPS tests were performed to characterize the wear of the $\mathrm{TiB}_{2}$ coated cutting tool versus uncoated. The validation model was done with the real test results. They concluded that the $\mathrm{TiB}_{2}$ coating is more efficient at lower shear rates. The wear performance is identical to the uncoated tool, for high cutting speeds.

- Michailidis [48] studied PVD coating properties that depend on the milling temperature of Ti6Al4V. For this study, it was used some specific conditions, such as the variation of the shear rate and a temperature range between $23^{\circ} \mathrm{C}$ and $400{ }^{\circ} \mathrm{C}$. Impact and nanoindentation tests were also carried out. The FEM was also used in this study to determine the shear stresses and temperatures. The objective of the study was to understand the properties behavior that is dependent on the working temperature and thus to understand the influence of this on the useful life of the coated tools and uncoated ones.

\section{Computational Fluid Dynamics (CFD)}

As already seen in Section 3, the CFD simulation brought answers to some engineering problems. In this section, CFD simulation will be discussed. This one is widely used to simulate, study, improve or optimize these problems [85-88]. It is possible to find research in different areas, such as aerodynamics of aircraft and vehicles, hydrodynamics of ships, turbomachinery, environmental engineering, hydrology and oceanography, process sciences, biomedical, pharmaceuticals, nuclear safety, energy production, thermal balance, among many others [34,40-42,69,87]. CFD techniques were integrated into the development and manufacture of aircraft and jet engines from the 1960s. In recent decades they have also been applied in the designs of internal combustion engines and gas turbine combustion chambers. Nowadays, CFD is widely used in the automotive industry, for example, in predicting drag forces and under-bonnet air flows. The CFD tool is increasingly important in product design and in industrial processes. Since the 1990s, there has been a boom due to the availability of hardware and software, as well as the increasing number of researchers [69].

The analysis of the engineering problems that use CFD has a high degree of complexity. In these studies, the characterization of the problem, as well as the variables and the constants used, call for the processors of the computers to be effectively powerful. In these cases, it is important to simplify the problem, but without impairing the characterization of the problem. It is necessary to have a balance between the necessary detail to characterize the problem and the number of variables to work because it will increase the computational effort. If the variables to work are many, it is very important to simplify them so that the simulation is more efficient and faster [89]. Moreover, the fluid flow problems that are studied with the CFD are structured around numerical algorithms [87].

Regarding the preprocessor, the simulation software has a user-friendly interface for the researcher submit the structured input data in a suitable way for the use by the next stage, analysis/solver. This step is very important because it will influence the next steps. If the data is not the most suitable, the solver will increase the resolution time or it will not be able to solve. The problem characterization is an indispensable part. Also, in preprocessing, the definition of the geometry to be studied, the mesh generation and its size, the selection of the physical phenomena to be studied, as well as the definition 
of the properties and the boundary conditions must also be done carefully. For example, a study of a fluid problem, such as temperature, velocity, pressure, etc., is defined within each cell, namely, at nodes. The resolution will depend on the number of cells used in the mesh. The higher the number of cells, the greater will be the accuracy, however, the calculation time will be longer and more powerful computer will be needed. Everything done in excess will lead to an increase in a computational effort $[87,90]$. In simulation software, predefined solvers are available which are dedicated to specific areas. For example, to include the pressure solver, by default, Navier-Stokes is available.

In the second element, Solver, nothing can be done due to the interferences that can cause and influence the final result. After the preprocessing is performed very carefully, it is time for the solver perform all calculations as expected. The time assigned to this phase is directly related to the computer hardware, especially the processors. The most common errors in constructing the model are the quality of the elements and nodes, invalid properties of the materials, inadequate mesh and insufficiently restricted model.

The last stage is the post-processing. In this phase, it is important to join the results from the solver with the knowledge about the software and the problem. The accuracy of the computer does not guarantee the accuracy of the results. Throughout the study process, it is important to collect data, characterize and structure the problem, define the study variables, choose the appropriate solver, to have a good computer and software, know how to interpret the results, and know well the problem. Next, it can be seen some complex works solved using CFD.

- Adebiyi et al. [91] developed a CFD model to simulate the cold spray coating process. Due to the high degree of complexity, it was necessary to create a CFD model that characterizes it, selecting carefully the main parameters of the process, for example, the inlet temperature, velocity distribution and pressure in the cold spray nozzle. With the model already created, it was possible to optimize some of these parameters, achieving coatings with greater hardness and lower porosity.

- Abdel-Fattah et al. [24] developed a CFD model to simulate and study an industrial Claus reactor. In the model, the flow fields and the chemical reactions were predicted for two different industrial cases. The model was validated by comparing the results of the simulation and the actual experimental data. The authors made the proposal to be tested through the CFD model developed with reactors of different technology as future work.

- Crose et al. [92] developed a multiscale CFD simulation model to study the PECVD of thin-film solar cells. In the manufacture of thin silicon films for solar cells and in the microelectronics industry, the commonly used method is PECVD because it has moderate operating temperatures and the costs associated with the process are low. In the developed CFD-2D model, plasma chemistry and transport phenomena inside the reactor were predicted.

- Vandewalle et al. [32] have done a study concerning the formation of coke in 3D steam cracking reactor geometries. A CFD-3D model was developed to simulate the object of study. The algorithm was based on dynamic mesh generation. The influence of the increasing coke layer was studied with reactor pressure and temperatures. It was concluded that the ribbed reactors outperform the remainder. Fluid dynamics, coke formation and product yield are influenced because the tubular geometries are not uniform.

- Ghasemzadeh et al. [29] studied a Pd-Ag membrane tubular reactor. A CFD-2D isothermal model was presented to study an ethylbenzene (EB) dehydrogenation of the Pd-Ag membrane reactor. The performance of two different flow patterns was also compared to the traditional reactor. For the analysis of the driving force, the model provides real information about pressure, velocity, among others. The validation was made comparing the actual data with the simulated data and some similarity was found.

- Mirvakili et al. [27] developed a CFD model to identify and solve the condensation problem in the gas-cooled reactor. The objective was to decrease the temperature at the end of the reactor. 
The condensation problem occurred after four years of operation. It was found that the source of the problem is the inadequate design inside the reactor. This causes the poor distribution of fluid within the reactor.

- Phuan et al. [28] created a CFD model to simulate the coating process in a Photo Fuel Cell (PFC) reactor. In the model, the performance of the anodic chamber was predicted. After the model was created, simulations were done and it was concluded that the model is very useful to provide the conditions for effective treatment of water and the solar hydrogen in the cathodic chamber.

- Tapia et al. [25] developed a CFD thermal model to study and evaluate the performance of a solar tubular reactor design. In the developed project it was shown that the tool obtained good results in the identification of the weaknesses exhibited by the solar tubular reactor. The model has some flexibility, allowing simulation with different operating conditions.

- Sen et al. [93] studied the self-propagation of the exothermic reaction in $\mathrm{Ti} / \mathrm{Al}$ reactive multilayers using CFD simulations. After the CFD model has been created, it was possible to show an enormous potential to simulate the exothermic reaction in the $\mathrm{Ti} / \mathrm{Al}$ nanoscale sheet and also show that time is temperature dependent.

- Prades et al. [26] investigated the effect of the integration of fluid dynamics in fixed biofilm reactors. For this work, 2D bioreactor models with three different tools were developed and evaluated. They are Aquasim, Matlab and CFD. The results of the simulation were validated with experimental measurements inside the biofilm. The developed CFD models describe the mass transfer phenomena accurately in fixed bed bioreactors.

- Menon et al. [33] developed a 2D model to simulate the behavior of the Chemical Looping Combustion (CLC) fuel reactor system with the help of CFD-2D. In the study, the performance of the ash from Indian coal was analyzed. Another stage of the work focused on the study of the system without ashes. In this step, it was concluded that the $\mathrm{CuO}$ performs better than the mixed carrier and $\mathrm{Fe}_{2} \mathrm{O}_{3}$. It was also found that the mixed compound improved performance when ash was included.

- Silva et al. [30] carried out a study on diesel hydrotreating in a laboratory scale trickle bed reactor (TBR). In this work, the CFD model was developed using a multi-phase Eulerian-Eulerian approach to study the reaction assessment and fluid dynamics. The importance of parameters such as speed, pressure, temperature and gas used for reactor performance was verified. In the CFD model, it is possible to obtain values very close to the real ones and it is possible to calculate the reaction rates and the mass transfers.

- Guo et al. [94] studied the transport and reaction in packed bed chemical looping combustion (CLC) reactors. For the development of this work, it was necessary to create a CFD simulation model of discrete particles to simulate the CLC. The developed model provides the flow, temperature and species in detail because it is a method which uses discrete particles.

- Kapopara et al. [36] studied and analyzed the $\mathrm{ZrN}$ coating deposited by cathodic spray through CFD. In this work, it was necessary to create a CFD-3D model to study the parameters of the cathodic spraying process, such as velocity, pressure, mass flow, gas density and concentration profiles. It was concluded that the gas inlet is preponderant in the process, inside the chamber. This model allows to study the best geometry of the reactor and to find a gas flow more suitable to improve the coating.

- Kapopara et al. [35] studied the coating process inside the sputtering chamber. A CFD-3D model was created using the FLUENT-ANSYS ${ }^{\circledR}$ analysis package. In the simulation, it was possible to predict velocity, density, pressure and concentration distribution profiles of gas, argon and nitrogen, through the sputtering chamber reactor. The model was based on gas flow simulation and mixing behavior in the sputtering chamber. It was concluded that the model has the potential to be a decision support tool in the simulation of multi-component gas flow. 
- Bobzin et al. [31] studied the gas flow in the PVD reactor. A CFD model was developed to characterize the plasma reactor CC800/9 in an industrial context. With the model already developed, it is possible to simulate the neutral gases flow of argon and nitrogen. The software used was FLUENT-ANSYS ${ }^{\circledR}$. The algorithms used in the first and second models were Navier-Stokes equations and the Boltzmann equation, respectively. The Navier-Stokes equations were used to describe the gas flow, while in the second one, the Boltzmann equation was used for the kinetic approach. The results regarding the gas flow for the transition regime were different. The model, with Boltzmann's equations, was able to provide an exact physical description.

\section{CFD Simulation Software}

Technological evolution has brought the calculate ability higher than human capabilities. Thus, in recent years, there has also been a significant increase in the number of researchers interested in simulation. CFD is not only used for ships, airplanes, and racing cars. Nowadays, the simulation tools are used in the companies by engineers specialized in a great variety of products, namely in the development and the improvement of the product. Solutions obtained by simulation have enabled every Engineer to make better and faster decisions. For these reasons, there has been an increase in the use of simulation software, so accuracy and functionality have also improved. At the beginning of the 21st century, the expansion of the CFD was at the world level. With the increased use of simulation tools to solve real problems, a lot of software was developed. Each software has its specificity, for example, the calculation capacity with the algorithms adopted for each specific area of study, the graphical interface that they provide to the user, some software work at a lower level of programming, friendly interface, among others. In general, simulation programs are based on the $\mathrm{C}++$ or Python programming language. Some brands of simulation software make it possible to use them for free and others have direct authoring. This section will present some software available in the market.

ANSYS-FLUENT ${ }^{\circledR}$ software is a CFD simulation tool. It helps engineers to design innovative products, optimize performance, reduce development costs by shortening the design cycle, and puts the product on the market faster. Research Areas of Industrial and Rotary Machines, Energy, Combustion, Marine, Consumer Products, Electronics, Health and Medical Devices, Architecture, Agriculture and others, benefit from simulation software such as FLUENT ${ }^{\circledR}$ [95]. FLUENT ${ }^{\circledR}$ includes well-validated physical modelling capabilities to deliver fast, accurate results across the widest range of CFD and multiphysics applications. FLUENT ${ }^{\circledR}$ is a software that has been the subject of many research papers and industry validation. This acquired knowledge is used for future work. The reference data shows that users complete the workflow with 50\% less uptime [96]. There are already several options of choice regarding the physics types, such as Turbulence Modeling, Thermal Management, Turbomachinery, Fluid-Structure Interaction, and Multiphase Flows among others. This software has a student version, but the existing version for the industry has a copyright cost. There are also applications developed to interact with or be incorporated into other software. For example, FloEFD ${ }^{\circledR}$, from Siemens ${ }^{\circledR}$, is a 3D computational fluid dynamics analysis solution built into the major mechanical computer-aided design, such as CATIA V5, Creo, Siemens NX, Solid Edge, SolidWorks and Inventor. This scenario allows users to transfer the CFD simulation to the design process quickly by helping engineers make the decision. FloEFD is an efficient CFD tool integrated with CAD workflows, including Inventor and SolidEdge. With this tool, engineers work directly on their CAD model to prepare and evaluate their simultaneous CFD simulation [97].

FloEFD ${ }^{\circledR}$ for CATIA V5 ${ }^{\circledR}$, Creo $^{\circledR}$, Siemens NX ${ }^{\circledR}$, Solid Edge ${ }^{\circledR}$, SolidWorks ${ }^{\circledR}$ and Inventor ${ }^{\circledR}$ is a CFD analysis tool that is incorporated into them. Thus, engineers can work with CFD and the design process, identifying and correcting problems more quickly. This easy and quick way of working allows one to increase productivity between 2 times and 40 times [98-102]. Thousands of successful companies around the world and more than 100,000 users or researchers use SimScale ${ }^{\circledR}$ in the design validation process. It is also widely used to test and optimize product development projects by product 
designers and engineers working in the HVAC (Heating, Ventilation \& Air-Conditioning), Consumer Electronics, AEC (Architecture, Engineering and Construction), and Packaging and Containers markets. This software helps users in different physics types, such as, incompressible and compressible flow; laminar and turbulent flow; mass and thermal transport; multiphase flow; advanced modelling; fluid-solid body interaction [103].

PowerFlow ${ }^{\circledR}$ is another CFD simulation tool widely used in aerodynamics: aerodynamic efficiency, vehicle handling and driving dynamics; thermal management: cooling airflow; thermal protection, brake cooling, electronics and battery cooling; climate control: cabin comfort, HVAC unit \& distribution system performance, HVAC system and fan noise; powertrain: exhaust systems and engine block [104]. Users do not need to install the software because Exa offers PowerFlow ${ }^{\circledR}$ over the web. It is possible to simulate and save simulation data in a cloud. Thus, companies do not need to have high-performance computers, and for this reason, projects become less expensive [105].

OpenFoam ${ }^{\circledR}$ is one of the most widely used free CFD software. It has a large user base in the area of engineering and science. The academic, as well as business community, use this free software for their projects to be less expensive and more efficient. Complex fluid fluxes involving chemical reactions, turbulence and heat transfer, acoustics, solids mechanics, and electromagnetism are developed and worked with OpenFOAM ${ }^{\circledR}$ software. The evolution of the software is due to updates every six months, in June and December. These updates include customer developments and community contributions. It is tested and validated by application specialists and development partners. Tests include regression behavior, code performance, scalability, and memory usage [106].

Another well-known simulation software CFD is COMSOL ${ }^{\circledR}$. The CFD module that belongs to COMSOL Multiphysics ${ }^{\circledR}$ simulation platform allows one to model and analyze projects in the area of fluid flow, including laminar and turbulent flow, incompressible and compressible flows, and single-phase and multiphase flows. This software is quite versatile because the simulation packages work in Windows ${ }^{\circledR}$, Mac $^{\circledR}$ and Linux ${ }^{\circledR}$ environments [107].

There is software known in the market in other areas that will evolve by adding plugins. For example, Blender ${ }^{\circledR}$ is known for modelling, manipulation, animation rendering, simulation, game creation, and so on. This software is the free and open source and has a plugin, FLIP Fluids ${ }^{\circledR}$ for 3D simulation of liquids. This plugin, created by Ryan Guy and Dennis Fassbaender, gives the ability to create high-quality fluid effects [108].

Simcenter $3 \mathrm{D}^{\circledR}$, in particular, STAR-CCM $+{ }^{\circledR}$, is a Siemens ${ }^{\circledR}$ 3D simulation software with an independent simulation environment. This simulation software allows working in: acoustics, composites, fluid dynamics simulation, motion, structural and thermal. It also responds to the industry needs by providing a metaphysical package dominated by the flow. This allows to model and studies the interaction between a gas or liquid with solid objects taking into account erosion, deposition, transport of particles, heat transfer, stress induced by the flow, combustion and chemical reaction [109].

Flow- $3 \mathrm{D}^{\circledR}$ is another brand that provides 3D simulation software for students, teachers, researchers and industry professionals. Flow-3 $\mathrm{D}^{\circledR}$ is available for installation on the personal computer or on the cloud. Flow-3D ${ }^{\circledR}$ is targeted at problems in the following areas: biomedicine, water civil infrastructure, additive manufacturing, inkjet printing, laser welding, aerospace, consumer products, power and automotive. The Flow-3D Cloud allows the user to simulate their projects without having a high-performance computer. According to the user needs, the company offers packs with different costs [110].

MATLAB ${ }^{\circledR}$-FEATool ${ }^{\circledR}$ Multiphysics, has a toolbox simulation for fluid dynamics, heat transfer, chemical engineering and structural mechanics. FEATool ${ }^{\circledR}$ Multiphysics offers a friendly interface and a great tool with geometry and CAD design, automatic grid generation, solver, and post-processing. This toolbox is designed for 1D simulation, 3D simulation, continuous modeling, design analysis, dynamic, graphical, motion and stochastic modelling [111]. 
NEI Nastran ${ }^{\circledR}$ makes available to its users finite element analysis software (FEA), engineering simulation and virtual testing. NEI software offers to its users simulation tools for linear and non-linear structural stress, deformation, fatigue kinematic deformation, vibration, dynamics, heat transfer and fluid dynamic and other performance parameters of product designs [112].

Conself $^{\circledR}$ is a computer-aided engineering (CAE) platform used in projects by engineers. The solver used by Conself $f^{\circledR}$ in CFD is open source technologies OpenFOAM ${ }^{\circledR}$. For example, this software solves incompressible/compressible single material flow, multiphase non-compressible flows, passive scalar transport for HVAC, turbomachinery and flow with particles. Conself ${ }^{\circledR}$ also offers its users a cloud to save the data and also to run the simulation, charging only the time that the user needs. In this process, Conself ${ }^{\circledR}$ also provides specialized support to help. In CFD projects, you can increase efficiency, maximize heat exchange performance, minimize drag and fluid dynamics losses, and so on [113].

AutoDesk ${ }^{\circledR}$ CFD is a software developed to study and simulate projects in the area of fluids and thermal. With this software, it is possible to study: the most appropriate design, and the phenomena occurring in fluid flow and heat transfer. It also enables intelligent mesh creation, generates turbulence models, and delivers high-performance resolution. AutoDesk ${ }^{\circledR}$ CFD has different packages, with the corresponding prices, depending on the user's needs [114].

Ingrid Cloud ${ }^{\circledR}$ provides a CFD simulation service based on closed source software offering fully automated high fidelity simulations. The software used, helps to improve fluid dynamics with the power of supercomputers through the cloud. It enables mesh refinement based on error estimation. The service provided is divided into different packs. The support provided to the projects, the simulations number, as well as the level of projects calculation are some of the factors that differentiate the cost. In order to compare costs between the traditional CFD and the service offered by Ingrid Cloud, you should consider the appropriate computer and software to run the project [115].

Simright ${ }^{\circledR}$ is another platform that offers cloud-based tools for modeling, simulation, and optimization for users to access through a web browser. This service is prepared to provide the software and the hardware, avoiding the costs of the same to the users. These ones are implanted in the remote servers. This platform has two separate packs available, one free and one more complete with a monthly cost attributed [116].

MantiumFlow $^{\circledR}$ is a CFD simulation tool that involves open source, OpenFOAM ${ }^{\circledR}$. With this software, it only needs to provide the geometry and select the most suitable template. MantiumFlow ${ }^{\circledR}$ is available in four packs. One is a free software, another allows a three months license, the third has a one-year license and fourth has a one-year license adding professional support [117].

Surely, it is not possible to state that a certain software is the best or the worst because each case is a case and, in this context, there is some software that is most suitable for certain studies. There will always be one or more software that better fits in one context and less good in others. In selecting the software, one will need to take into account the important criteria. For example, the cost of software, support for problem-solving, research or industrial work in the area with a particular software to be more reliable, among others.

As can be seen, fortunately, there are already many software solutions available in the market for CFD simulation. Due to this offer, it becomes difficult to choose the most suitable because they offer different options each. For example, it is important to know which software is most suitable for the project in relation to the algorithms used. However, it should also be taken into account if one has hardware capable of taking advantage of the software capabilities. An estimate of the simulation cost in the project must also be performed. It is possible to use a cloud-based simulation service, avoiding a powerful and expensive computer. When choosing Cloud, you need to check whether it is best to purchase an annual license or a license that pays only the simulation time. The diagram depicted in Figure 5 presents a way of supporting software decision making.

An important question for choosing the software is: do you have a powerful computer to create the model and simulate? If you do not have, you should look for the cloud service with included 
software. This option may have high costs. If one is able to do the opposite, one can look for software that allows install it on your own computer by paying for a license or open source software.

Once one understands the group pointed out as conditions, it is possible to verify, from the available options, the one that best fits the project needs. It is possible to verify which software is the most used in solving similar problems, if it has some type of support to help in the work development, among other parameters. As it can be seen in the diagram of Figure 6, Group I include a CFD software well-known in the market. They are software with high license costs and users need high simulation skills to work. However, these software are evolved a lot and now, they allow the user to choose and control parameters, such as surface and volume mesh, among others. Usually, they also offer good user support.

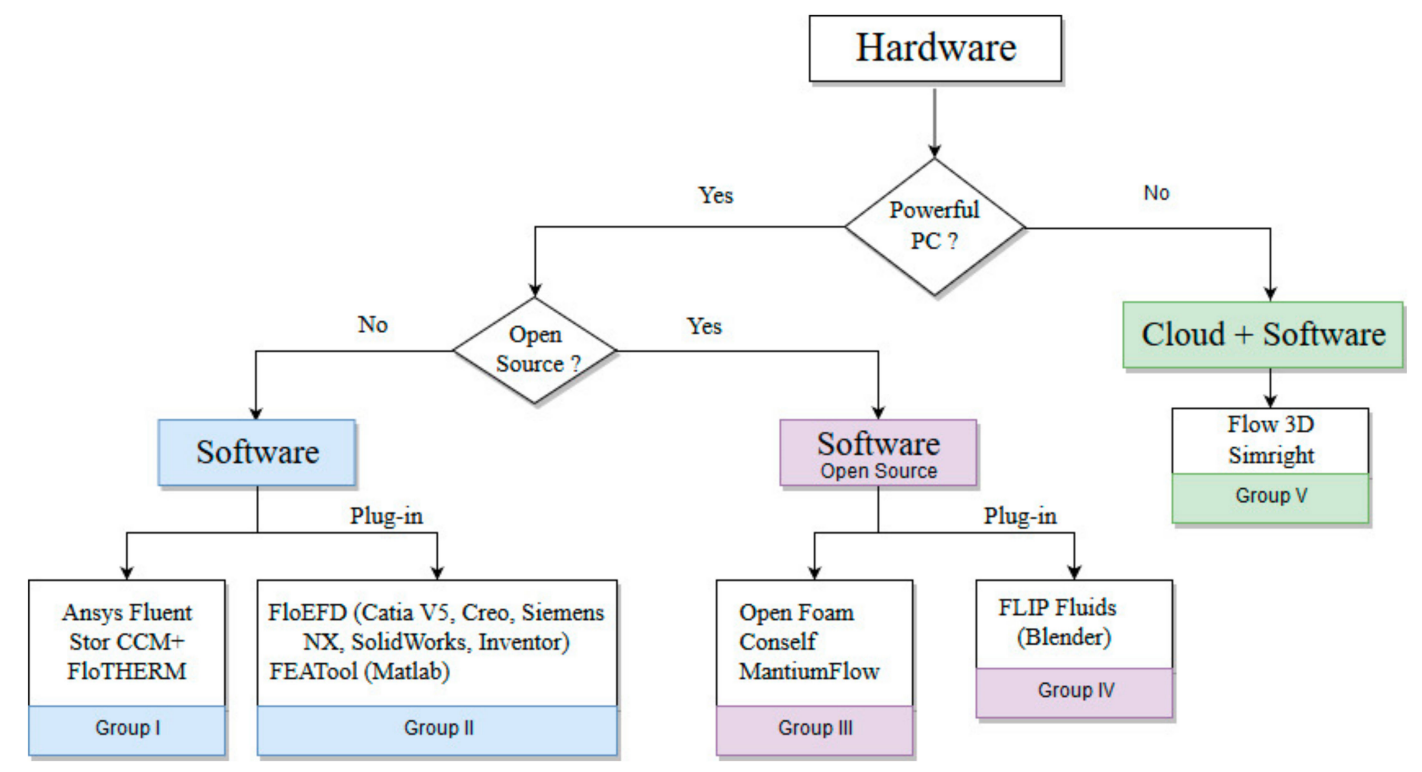

Figure 6. Software decision support.

In Group II, it is possible to choose software that will complement and be incorporated in other software to enable them in CFD calculation. With these plugins installed in software such as SolidWorks, Catia V5, Creo, among others, the user can carry out the CFD simulation without changing the program, maintaining the work environment.

Group III, as can be seen in Figure 5, includes open source CFD simulation software well-known in the market. For single-phase flow simulations, these software are good and are relatively fast. If it is two phases, it may take a while to develop the code, depending on the user experience.

Group IV, is at the same level of Group III, having the difference of not being independent software, but a plug-in that will work incorporated in other software. In this case, it prevents the user from changing software, for example, FLIP Fluids will give CFD simulation capability in Blender software.

Finally, Group V gives users the conditions to simulate in CFD, even if it does not have a performant computer. This option may be a consequence of the hardware not having the minimum characteristics necessary for the software to function in perfect conditions. Simulation data is also saved on the cloud by freeing the disk from the computer. This type of service offers several packs, such as a basic and very limited free version, to an annual fee version with support.

In summary, there is no right recipe for every problem neither software $100 \%$ appropriate. All have advantages and disadvantages in their use. The choice will depend on your organization's requirements, available resources and time, skills, and other factors. 


\section{Concluding Remarks}

In the last years, the simulation had a huge growth. In this review, in Section 3, the evolution of engineering problem-solving methods was mentioned, namely the analytical methods, the experimental methods and the numerical methods, namely the simulation FEM and CFD, associated to the currently available technology.

The complex problems associated with PVD reactors have been solved through the development of simulation models. This form of resolution goes through characterizing the problem, validating the model and subsequently improving, resolving and even extrapolating to other problems. This process becomes cheaper, faster and more efficient, avoiding the cost associated with stopping production. This methodology was due to the appearance of new technologies, as well as the interested researchers in this field and the demand of the companies to be more competitive in the Market. The areas of heat transfer, fluid flow, aerodynamics, mass transport, electromagnetic potential, among others, are often studied and optimized using 3D simulation. Table 2 shows the examples described in the literature about FEM and CFD applications, discussed in previous chapters.

In this paper, it was verified that the FEM is focused to solve problems based on substrate, while the CFD is focused on solving PVD coating process problems, namely physical problems, such as transport of mass, velocity profiles, thermal performance, pressure profiles, among others. In fact, there are already some CFD simulation jobs to solve problems associated with several types of reactors, although there are a few associated with PVD reactors. The available software on the market was also dissected in this work. To assist in choosing the software, in section 6 there is a diagram to guide the user in that process.

In the last two decades, there has been a significant increase of new simulation software in the market, some free, some with reserved copyright, and there are platforms that provide clouds where the user has access from any computer with an internet connection. These platforms have several packs available, and the most complete pack provides the user with software, problem-solving support and a space to store the simulation data. In other words, the user does not need a powerful computer to simulate, just a browser and an internet connection. Some software and platforms have support services to assist users in solving problems that arise in projects.

Table 2. Works carried out using FEM and CFD.

\begin{tabular}{|c|c|c|c|c|c|}
\hline \multicolumn{3}{|c|}{ FEM } & \multicolumn{3}{|l|}{ CFD } \\
\hline Study & Software Used & Ref. & Study & Software Used & Ref. \\
\hline $\begin{array}{l}\text { PVD coatings mechanical } \\
\text { properties prediction }\end{array}$ & ANSYS 12.0 & [7] & $\begin{array}{l}\text { Creation of a three-dimensional } \\
\text { model describing flow fields and } \\
\text { chemical reactions in Claus reactors }\end{array}$ & $\begin{array}{l}\text { COMSOL } \\
\text { Multiphysics }\end{array}$ & [24] \\
\hline $\begin{array}{l}\text { Tribological performance and } \\
\text { wear of coated cutting tools }\end{array}$ & AdvantEdg 7.1 & [16] & $\begin{array}{l}\text { Development of the model to } \\
\text { evaluate the thermal performance of } \\
\text { a solar tubular reactor }\end{array}$ & ANSYS-CFX 14.0 & [25] \\
\hline $\begin{array}{l}\text { Computer simulation of internal } \\
\text { stresses on the PVD coatings }\end{array}$ & ANSYS & [17] & $\begin{array}{l}\mathrm{CFD} \text { analysis of } \mathrm{Pd}-\mathrm{Ag} \text { membrane } \\
\text { reactor performance during process }\end{array}$ & $\begin{array}{l}\text { COMSOL } \\
\text { Multiphysics 5.2.1 }\end{array}$ & [29] \\
\hline Coating fracture surface study & ABAQUS & [77] & $\begin{array}{l}\text { Fluid dynamics and reaction } \\
\text { assessment of diesel oil hydro } \\
\text { treating reactors }\end{array}$ & ANSYS-CFX 14.0 & [30] \\
\hline $\begin{array}{l}\text { Film thickness effect on } \\
\text { mechanical properties of PVD } \\
\text { coated tools }\end{array}$ & DEFORM and ANSYS & [78] & $\begin{array}{l}\text { Neutral gas flow simulations in an } \\
\text { industrial PVD reactor }\end{array}$ & $\begin{array}{l}\text { ANSYS } \\
\text { FLUENT } 14.0\end{array}$ & [31] \\
\hline $\begin{array}{l}\text { Defects and material } \\
\text { deformation study }\end{array}$ & LS-DYNA & [79] & $\begin{array}{l}\text { Prediction of velocity profiles, } \\
\text { pressure profiles, density profiles and } \\
\text { process gas distribution across the } \\
\text { sputtering chamber }\end{array}$ & ANSYS FLUENT & [35] \\
\hline $\begin{array}{l}\text { Estimate the thermo-mechanical } \\
\text { properties of plasma sprayed } \\
\text { composite coatings }\end{array}$ & $\begin{array}{l}\text { ANSYS-APDL } \\
\text { (Parametric } \\
\text { Design Language) }\end{array}$ & [83] & $\begin{array}{l}\text { Modeling on chemical looping } \\
\text { combustion (CLC) reactor with } \\
\text { a finite volume based CFD method }\end{array}$ & Not defined & [94] \\
\hline
\end{tabular}

After analyzing the literature it is observed that FEM is generally used to study, optimize or solve problems associated with mechanical properties, namely, adhesion, wear, stresses in the coating, 
the influence of the coating thickness, among others. Regarding CFD, there are studies associated with solving problems in aerodynamics, fluid flow, temperature, mass transport, heat transfer, among others. The literature shows that there are also successful works that contemplate other types of reactors studied by CFD, increasing the interest of the researchers in the application of CFD simulation in the PVD coatings. The study focus of the first works was the optimization and/or resolution of problems associated with the characteristics and properties of the materials, but now, the tendency is to focus attention on the coating process in the PVD reactor, in an industrial context, using the simulation and avoiding the spend of time in the manufacturing process. The goal is to improve the process, the product and make the companies more competitive in the market.

There are still many problems to be studied and solved using the CFD simulation for PVD reactors, namely to make the process more efficient by improving the plasma spraying and its density, cycle times, geometry inside the reactor chamber, the gases inlet, the position of the substrates and the speed of rotation, the use of the gas and the combination of the gases to assign the characteristics of the desired coatings, among others.

Author Contributions: Conceptualization, G.P. and F.S.; Methodology, G.P. and F.S.; Writing-Original Draft Preparation, G.P.; Writing—Review \& Editing, F.S. and A.B.; Supervision, J.P., J.M. and F.S.

Funding: This research received no external funding.

Acknowledgments: Authors Gustavo Pinto and Andresa Baptista thank the financial support of CIDEM/ISEP.

Conflicts of Interest: The authors declare no conflict of interest.

\section{References}

1. Silva, F.J.G.; Martinho, R.P.; Alexandre, R.J.D.; Baptista, A.P.M. Wear resistance of TiAlSiN thin coatings. J. Nanosci. Nanotechnol. 2012, 12, 9094-9101. [CrossRef] [PubMed]

2. Silva, F.J.G.; Martinho, R.P.; Alexandre, R.J.D.; Baptista, A.P.M. Increasing the wear resistance of molds for injection of glass fiber reinforced plastics. Wear 2011, 271, 2494-2499. [CrossRef]

3. Silva, F.; Martinho, R.; Andrade, M.; Baptista, A.; Alexandre, R. Improving the wear resistance of moulds for the injection of glass fibre-reinforced plastics using PVD coatings: A comparative study. Coatings 2017, 7, 28. [CrossRef]

4. Skordaris, G.; Bouzakis, K.; Kotsanis, T.; Charalampous, P.; Bouzakis, E.; Breidenstein, B.; Bergmann, B.; Denkena, B. Effect of PVD film's residual stresses on their mechanical properties, brittleness, adhesion and cutting performance of coated tools. CIRP J. Manuf. Sci. Technol. 2017, 18, 145-151. [CrossRef]

5. Thakur, A.; Gangopadhyay, S. Influence of tribological properties on the performance of uncoated, CVD and PVD coated tools in machining of Incoloy 825. Tribol. Int. 2016, 102, 198-212. [CrossRef]

6. Chen, J.; Ji, R.; Khan, R.; Li, X.; Beake, B.; Dong, H. Effects of mechanical properties and layer structure on the cyclic dynamic loading of TiN-based coatings. J. Surf. Coat. Technol. 2011, 206, 522-529. [CrossRef]

7. Sliwa, A.; Mikuła, J.; Gołombek, K.; Tanski, T.; Kwasny, W.; Bonek, M.; Brytan, Z. Prediction of the properties of PVD/CVD coatings with the use of FEM analysis. J. Appl. Surf. Sci. 2016, 388, 281-287. [CrossRef]

8. Martinho, R.P.; Silva, F.J.G.; Baptista, A.P.M. Cutting forces and wear analysis of $\mathrm{Si}_{3} \mathrm{~N}_{4}$ diamond coated tools in high speed machining. Vacuum 2008, 82, 1415-1420. [CrossRef]

9. Bouzakis, K.; Skordaris, G.; Klocke, F.; Bouzakis, E. A FEM-based analytical-experimental method for determining strength properties gradation in coatings after micro-blasting. J. Surf. Coat. Technol. 2009, 203, 2946-2953. [CrossRef]

10. Rao, R.V. The significant application of fem to evaluate the mechanical properties of thin films. Procedia Mater. Sci. 2014, 6, 1260-1265. [CrossRef]

11. Martinho, R.P.; Andrade, M.F.C.; Silva, F.J.G.; Alexandre, R.J.D.; Baptista, A.P.M. Microabrasion wear behaviour of TiAlCrSiN nanostructured coatings. Wear 2009, 267, 1160-1165. [CrossRef]

12. Fernandes, L.; Silva, F.J.G.; Andrade, M.F.; Alexandre, R.; Baptista, A.P.M.; Rodrigues, C. Increasing the stamping tools lifespan by using Mo and $\mathrm{B}_{4} \mathrm{C}$ PVD coatings. Surf. Coat. Technol. 2017, 325, 107-119. [CrossRef] 
13. Nunes, V.; Silva, F.J.G.; Andrade, M.F.; Alexandre, R.; Baptista, A.P.M. Increasing the lifespan of high-pressure die cast molds subjected to severe wear. Surf. Coat. Technol. 2017, 332, 319-331. [CrossRef]

14. Martinho, R.P.; Silva, F.J.G.; Alexandre, R.J.D.; Baptista, A.P.M. TiB 2 Nanostructured coating for GFRP injection moulds. J. Nanosci. Nanotechnol. 2011, 11, 5374-5382. [CrossRef] [PubMed]

15. Silva, F.J.G.; Casais, R.C.B.; Martinho, R.P.A.; Baptista, P.M. Mechanical and tribological characterization of $\mathrm{TiB}_{2}$ thin films. J. Nanosci. Nanotechnol. 2012, 12, 9187-9194. [CrossRef] [PubMed]

16. Paiva, J.; Shalaby, M.; Chowdhury, M.; Shuster, L.; Chertovskikh, S.; Covelli, D.; Junior, E.; Stolf, P.; Elfizy, A.; Bork, C.; et al. Tribological and wear performance of carbide tools with $\mathrm{TiB}_{2} \mathrm{PVD}_{\text {coating }}$ under varying machining conditions of TiAl6V4 aerospace alloy. Coatings 2017, 7, 187. [CrossRef]

17. Śliwa, A.; Dobrzański, L.; Kwaśny, W.; Sitek, W. The computer simulation of internal stresses on the PVD coatings. Arch. Comput. Mater. Sci. Surf. Eng. 2009, 1, 183-188.

18. Minkowycz, W.J.; Sparrow, E.M.; Murthy, J.Y. Handbook of Numerical Heat Transfer, 2nd ed.; Wiley: Hoboken, NJ, USA, 2006; p. 984.

19. Erhunmwun, I.D.; Ikponmwosa, U.B. Review on finite element method. J. Appl. Sci. Environ. Manag. 2017, 21,999-1002. [CrossRef]

20. Courant, R. Variational methods for the solution of problems of equilibrium and vibrations. Bull. Am. Math. Soc. 1943, 49, 1-23. [CrossRef]

21. Turner, M.; Clough, R.W.; Martin, H.H.; Topp, L. Stiffness and deflection analysis of complex structures. J. Aeronaut. Sci. 1956, 23, 805-823. [CrossRef]

22. Zienkiewicz, O.C.; Cheung, Y.K. Finite elements in the solution of field problems. Engineer 1965, 220, 507-510.

23. Wilson, E.L.; Nickel, R.E. Application of the finite element method to heat conduction analysis. Nucl. Eng. Des. 1966, 4, 276-286. [CrossRef]

24. Abdel-Fattah, A.; Fateen, S.; Moustafa, T.; Fouad, M. Three-dimensional CFD simulation of industrial Claus reactors. Chem. Eng. Res. Des. 2016, 112, 78-87. [CrossRef]

25. Tapia, E.; Iranzo, A.; Pino, F.; Rosa, F.; Salva, J. Methodology for thermal design of solar tubular reactors using CFD techniques. Int. J. Hydrogen Energy 2016, 41, 19525-19538. [CrossRef]

26. Prades, L.; Dorado, A.; Climent, J.; Guimerà, X.; Chiva, S.; Gamisans, X. CFD modelling of a fixed-bed biofilm reactor coupling hydrodynamics and biokinetics. Chem. Eng. J. 2017, 313, 680-692. [CrossRef]

27. Mirvakili, A.; Bakhtyari, A.; Rahimpour, M. A CFD modelling to investigate the impact of flow mal-distribution on the performance of industrial methanol synthesis reactor. Appl. Therm. Eng. 2018, 128, 64-78. [CrossRef]

28. Phuan, Y.; Ismail, H.; Garcia-Segura, S.; Chong, M. Design and CFD modelling of the anodic chamber of a continuous PhotoFuelCell reactor for water treatment. Process Saf. Environ. Prot. 2017, 111, 449-461. [CrossRef]

29. Ghasemzadeh, K.; Zeynali, R.; Bahadori, F.; Basile, A. CFD analysis of Pd-Ag membrane reactor performance during ethylbenzene dehydrogenation process. Int. J. Hydrogen Energy 2017, 43, 7675-7683. [CrossRef]

30. Silva, A.; Monteiro, C.; Souza, V.; Ferreira, A.; Jaimes, R.; Fontoura, D.; Nunhez, J. Fluid dynamics and reaction assessment of diesel oil hydrotreating reactors via CFD. Fuel Process. Technol. 2017, 166, 17-29. [CrossRef]

31. Bobzin, K.; Brinkmann, R.; Mussenbrock, T.; Bagcivan, N.; Brugnara, R.; Schäfer, M.; Trieschmann, J. Continuum and kinetic simulations of the neutral gas flow in an industrial physical vapor deposition reactor. Surf. Coat. Technol. 2013, 237, 176-181. [CrossRef]

32. Vandewalle, L.; Cauwenberge, D.; Dedeyne, J.; Gee, K.; Marin, G. Dynamic simulation of fouling in steam cracking reactors using CFD. Chem. Eng. J. 2017, 329, 77-87. [CrossRef]

33. Menon, K.; Patnaikuni, V. CFD simulation of fuel reactor for chemical looping combustion of Indian coal. Fuel 2017, 203, 90-101. [CrossRef]

34. Chapela, S.; Porteiro, J.; Costa, M. Effect of the turbulence-chemistry interaction in packed-bed biomass combustion. Energy Fuels 2017, 31, 9967-9982. [CrossRef]

35. Kapopara, J.; Mengar, A.; Chauhan, K.; Rawal, S. CFD analysis of sputtered TiN coating. Materialstoday Proc. 2017, 4, 9390-9393. [CrossRef]

36. Kapopara, J.M.; Mengar, A.R.; Chauhan, K.V.; Patel, N.P.; Rawal, S.K. Modelling and analysis of sputter deposited ZrN coating by CFD. IOP Conf. Ser. Mater. Sci. Eng. 2016, 149, 012205. [CrossRef] 
37. Trieschmann, J. Neural gas simulation on the influence of rotating spokes on gas rarefaction in high-power impulse magnetron sputtering. Contrib. Plasma Phys. 2018, 58, 394-403. [CrossRef]

38. Chaney, J.; Liu, H.; Li, J. An overview of CFD modelling of small-scale fixed-bed biomass pellet boilers with preliminary results from a simplified approach. J. Energy Convers. Manag. 2012, 63, 149-156. [CrossRef]

39. Porteiro, J.; Collazo, J.; Patino, D.; Granada, E.; Gonzalez, J.; Míguez, J. Numerical modeling of a biomass pellet domestic boiler. Energy Fuels 2009, 23, 1067-1075. [CrossRef]

40. Karim, M.; Naser, J. Progress in numerical modelling of packed bed biomass combustion. In Proceedings of the 19th Australasian Fluid Mechanics Conference, Melbourne, Australia, 8-11 December 2014.

41. Collazo, J.; Porteiro, J.; Míguez, J.; Granada, E.; Gómez, M. Numerical simulation of a small-scale biomass boiler. Energy Convers. Manag. 2012, 64, 87-96. [CrossRef]

42. Duffy, N.; Eaton, J. Investigation of factors affecting channelling in fixed-bed solid fuel combustion using CFD. Combust. Flame 2013, 160, 2204-2220. [CrossRef]

43. Hoche, H.; Groß, S.; Oechsner, M. Development of new PVD coatings for magnesium alloys with improved corrosion properties. Surf. Coat. Technol. 2014, 259, 102-108. [CrossRef]

44. Silva, F.J.G.; Martinho, R.P.; Baptista, A.P.M. Characterization of laboratory and industrial $\mathrm{CrN} / \mathrm{CrCN} /$ diamond-like carbon coatings. Thin Solid Films 2014, 550, 278-284. [CrossRef]

45. Gouveia, R.M.; Silva, F.J.G.; Reis, P.; Baptista, A.P.M. Machining duplex stainless steel: Comparative study regarding end mill coated tools. Coatings 2016, 6, 51. [CrossRef]

46. Klocke, F.; Döbbeler, B.; Binder, M.; Kramer, N.; Grüter, R.; Lung, D. Ecological evaluation of PVD and CVD coating systems in metal cutting processes. In 11th Global Conference on Sustainable Manufacturing-Innovative Solutions, Proceedings of the 11th Global Conference on Sustainable Manufacturing, Berlin, Germany, 23-25 September 2013; Seliger, G., Ed.; Universitätsverlag der TU Berlin: Berlin, Germany, 2013; pp. 381-386.

47. Barshilia, H.C.; Ananth, A.; Khan, J.; Srinivas, G. Ar $+\mathrm{H}_{2}$ plasma etching for improved adhesion of PVD coatings on steel substrates. Vacuum 2012, 86, 1165-1173. [CrossRef]

48. Michailidis, N. Variations in the cutting performance of PVD-coated tools in milling Ti6Al4V, explained through temperature-dependent coating properties. Surf. Coat. Technol. 2016, 304, 325-329. [CrossRef]

49. Inspektor, A.; Salvador, P.A. Architecture of PVD coatings for metalcutting applications: A review. Surf. Coat. Technol. 2014, 257, 138-153. [CrossRef]

50. Momeni, S.; Tillmann, W. Investigation of these if-healing sliding wear characteristics of NiTi-based PVD coatings on tool steel. Wear 2016, 368-369, 53-59. [CrossRef]

51. Mubarak, A.; Hamzah, E.; Toff, M.R.M. Review of physical vapour deposition (PVD) techniques for hard coating. Jurnal Mekanikal 2005, 20, 42-51.

52. Maity, S. Optimization of processing parameters of in-situ polymerization of pyrrole on woollen textile to improve its thermal conductivity. Prog. Org. Coat. 2017, 107, 48-53. [CrossRef]

53. Kim, M.I.; Kim, S.; Kim, T.; Lee, D.; Seo, B.K.; Lim, C.-S. Mechanical and thermal properties of epoxy composites containing zirconium oxide impregnated halloysite nanotubes. Coatings 2017, 7, 231.

54. Hu, N.; Khan, M.; Wang, Y.; Song, X.; Lin, C.; Chang, C.; Zeng, Y. Effect of microstructure on the thermal conductivity of plasma sprayed $\mathrm{Y}_{2} \mathrm{O}_{3}$ stabilized zirconia (8\% YSZ). Coatings 2017, 7, 198. [CrossRef]

55. Jiang, X.; Yang, F.C.; Chenc, W.C.; Lee, J.W.; Chang, C.L. Effect of nitrogen-argon flow ratio on the microstructural and mechanical properties of AlSiN thin films prepared by high power impulse magnetron sputtering. Surf. Coat. Technol. 2017, 320, 138-145. [CrossRef]

56. Alamia, J.; Bolz, S.; Sarakinos, K. High power pulsed magnetron sputtering: Fundamentals and applications. J. Alloys Compd. 2009, 483, 530-534. [CrossRef]

57. Bagcivan, N.; Bobzin, K.; Theiß, S. $\left(\mathrm{Cr}_{1-x} \mathrm{Al}_{x}\right) \mathrm{N}$ : A comparison of direct current, middle frequency pulsed and high power pulsed magnetron sputtering for injection molding components. Thin Solid Films 2013, 528, 180-186. [CrossRef]

58. Holmberg, K.; Matthews, A. Coatings tribology_Properties, mechanisms, techniques and applications. In Surface Engineering; Briscoe, B.J., Ed.; Elsevier: Amsterdam, The Netherlands, 2009; p. 576.

59. Mattox, D. Handbook of Physical Vapour Deposition (PVD) Processing, 2nd ed.; Elsevier: Amsterdam, The Netherlands, 2010; p. 792.

60. Tracton, A.A. Coatings Technology Handbook, 3rd ed.; Taylor \& Francis: Boca Raton, FL, USA, 2006; p. 828. 
61. Mattox, D.M. The Foundations of Vacuum Coating Technology; Noyes Publications: Norwich, NY, USA, 2003; p. 60.

62. Martin, P.M. Handbook of Deposition Technologies for Films and Coatings: Science, Applications and Technology; Elsevier: Boston, MA, USA, 2010; p. 912.

63. Baptista, A.; Silva, F.J.G.; Pinto, G.; Porteiro, J.; Míguez, J.; Fernandes, L. On the physical vapour deposition (PVD) process evolution. Procedia Manuf. 2018, 17, 746-757. [CrossRef]

64. Rappaz, M.; Bellet, M.; Deville, M. Numerical Modeling in Material Science and Engineering; Springer: Berlin/Heidelberg, Germany, 2010; p. 539.

65. Enelund, M.; Larsson, S.; Malmqvist, J. Integration of a computational mathematics education in the mechanical engineering curriculum. In Proceedings of the 7th International CDIO Conference, Technical University of Denmark, Copenhagen, Denmark, 20-23 June 2011.

66. Hamming, R. Numerical Methods for Scientists and Engineers; McGraw-Hill: New York, NY, USA, $1962 ;$ p. 411.

67. Chapra, S.; Canale, R. Numerical Methods for Engineers, 6th ed.; McGraw-Hill: Lisbon, Portugal, $2010 ;$ p. 968.

68. Computer Simulations in Engineering. Available online: http:/ /www.statisticsviews.com/details/feature/ 10482673/Computer-Simulations-in-Engineering.html (accessed on 24 May 2018).

69. Versteeg, H.K.; Malalasekera, W. An Introduction to Computational Fluid Dynamics, 2nd ed.; Pearson Education: New York, NY, USA, 2007; p. 503.

70. Pinto, G.; Silva, F.J.G.; Baptista, A.; Porteiro, J.; Míguez, J.; Fernandes, L. A critical review on the numerical simulation related to physical vapour deposition. Procedia Manuf. 2018, 17, 860-869. [CrossRef]

71. Dhatt, G.; Touzot, G.; Lefrançois, E. Finite Element Method; Wiley: London, UK, 2013; p. 624.

72. Banabic, D. Advanced Methods in Material Forming; Springer: Berlin, Germany, 2007; p. 363.

73. Logan, D.L. A First Course in the Finite Element Method, 4th ed.; Thomson: Sydney, Australia, 2007; p. 844.

74. Campilho, R. Métodos de Elementos Finitos_Ferramentas para análise estrutural, Júlia Guimarães; Publindústria Edições Técnicas: Porto, Portugal, 2012; p. 205. (in Portuguese)

75. Rao, S.S. The Finite Element Method in Engineering, 5th ed.; Elsevier: Amsterdam, The Netherlands, $2011 ;$ p. 727.

76. Gosz, M. Finite Element Method-Applications in Solids, Structures, and Heat Transfer; Taylor \& Francis Group: Boca Raton, FL, USA, 2006; p. 400.

77. Skordaris, G.; Bouzakis, K.; Charalampous, P. A dynamic FEM simulation of the nano-impact test on mono- or multi-layered PVD coatings considering their graded strength properties determined by experimental-analytical procedures. Surf. Coat. Technol. 2015, 265, 53-61. [CrossRef]

78. Skordaris, G.; Bouzakis, K.; Kotsanis, T.; Charalampous, P.; Bouzakis, E.; Lemmer, O.; Bolz, S. Film thickness effect on mechanical properties and milling performance of nano-structured multilayer PVD coated tools. Surf. Coat. Technol. 2016, 307, 452-460. [CrossRef]

79. Bouzakis, K.; Gerardis, S.; Skordaris, G.; Bouzakis, E. Nano-impact test on a TiAlN PVD coating and correlation between experimental and FEM results. Surf. Coat. Technol. 2011, 206, 1936-1940. [CrossRef]

80. Wang, L.; Li, D.; Yang, J.; Shao, F.; Zhong, X.; Zhao, H.; Yang, K.; Tao, S.; Wang, Y. Modeling of thermal properties and failure of thermal barrier coatings with the use of Finite Element Methods: A review. J. Eur. Ceram. Soc. 2016, 36, 1313-1331. [CrossRef]

81. Wang, L.; Zhong, X.; Zhao, Y.; Yang, J.; Tao, S.; Zhang, W.; Wang, Y.; Sun, X. Effect of interface on the thermal conductivity of thermal barrier coatings: A numerical simulation study. Int. J. Heat Mass Transfer 2014, 79, 954-967. [CrossRef]

82. Beblein, S.; Breidenstein, B.; Denkena, B.; Pusch, C.; Hocheb, H.; Oechsner, M. Thermomechanical coating load in dependence of fundamental coating properties. Procedia CIRP 2017, 58, 25-30. [CrossRef]

83. Bolot, R.; Aussavy, D.; Montavon, G. Application of FEM to estimate thermo-mechanical properties of plasma sprayed composite coatings. Coatings 2017, 7, 91. [CrossRef]

84. Lofaj, F; Németh, D. The effects of tip sharpness and coating thickness on nanoindentation measurements in hard coatings on softer substrates by FEM. Thin Solid Films 2017, 644, 173-181. [CrossRef]

85. Wang, Z.J. Adaptive High-Order Methods in Computational Fluid Dynamics, 2nd ed.; World Scientific: Hackensack, NJ, USA, 2011; p. 459.

86. Patankar, S. Numerical Heat Transfer and Fluid Flow, 1st ed.; MacGraw-Hill: New York, NY, USA, $1980 ;$ p. 197.

87. Versteeg, H.; Malalasekera, W. An Introduction to Computational Fluid Dynamics-The Finite Volume Method; Longman Scientific \& Technical: London, UK, 1995; p. 257. 
88. Ferziger, J.; Peric, M. Computational Methods for Fluid Dynamics, 3rd ed.; Springer: New York, NY, USA, 2002; p. 423.

89. Meroney, R.; Ohba, R.; Leitl, B.; Kondo, H.; Grawe, D.; Tominaga, Y. Review of CFD Guidelines for Dispersion Modeling. Fluids 2016, 1, 14. [CrossRef]

90. ANSYS Fluent User's Guide; Release 15.0; ANSYS: Canonsburg, PA, USA, 2013.

91. Adebiyi, D.; Popoola, A.; Botef, I. Experimental verification of statistically optimized parameters for low-pressure cold spray coating of titanium. Metals 2016, 6, 135. [CrossRef]

92. Crose, M.; Tran, A.; Christofides, P. Multiscale computational fluid dynamics: Methodology and application to PECVD of thin film solar cells. Coatings 2017, 7, 22. [CrossRef]

93. Sen, S.; Lake, M.; Kroppen, N.; Farber, P.; Wilden, J.; Schaaf, P. Self-propagating exothermic reaction analysis in $\mathrm{Ti} / \mathrm{Al}$ reactive films using experiments and computational fluid dynamics simulation. Appl. Surf. Sci. 2017, 396, 1490-1498. [CrossRef]

94. Guo, X.; Zhu, Z. CFD based modeling on chemical looping combustion in a packed bed reactor. Chem. Eng. Sci. 2015, 138, 303-314. [CrossRef]

95. ANSYS. Available online: https:/ / www.ansys.com/products/fluids (accessed on 8 May 2018).

96. ANSYS Fluent. Available online: https://www.ansys.com/products/fluids/ansys-fluent (accessed on 8 May 2018).

97. Mentor, Siemens Business-FloEFD. Available online: https://www.mentor.com/products/mechanical/ floefd/ (accessed on 9 May 2018).

98. Mentor, Siemens Business-FloEFD for Catia V5. Available online: https:/ / www.mentor.com/products / mechanical/floefd/floefd-catia-v5/ (accessed on 9 May 2018).

99. Mentor, Siemens Business-FloEFD for Creo. Available online: https://www.mentor.com/products/ mechanical/floefd/floefd-creo/ (accessed on 9 May 2018).

100. Mentor, Siemens Business-FloEFD for Siemens NX. Available online: https:/ /www.mentor.com/products / mechanical/floefd/floefd-nx/ (accessed on 9 May 2018).

101. Mentor, Siemens Business-FloEFD Flexx. Available online: https://www.mentor.com/products/ mechanical/floefd/floefd-flexx/ (accessed on 9 May 2018).

102. Mentor, Siemens Business-FloEFD for Solid Edge. Available online: https://www.mentor.com/products/ mechanical/floefd/floefd-solid-edge/ (accessed on 9 May 2018).

103. Simulation Software Reinvented for the Web. Available online: https:/ / www.simscale.com (accessed on 11 May 2018).

104. Simulia PowerFLOW. Available online: https://exa.com/en/product/simulation-tools/powerflow-cfdsimulation (accessed on 11 May 2018).

105. Simulia ExaCloud. Available online: https:/ / exa.com/en/services/exacloud-simulation-tools (accessed on 11 May 2018).

106. OpenFoam. Available online: https:/ / www.openfoam.com/ (accessed on 15 May 2018).

107. Simulate Fluid Flow Applications with the CFD Module. Available online: https:/ www.comsol.com/cfdmodule (accessed on 15 May 2018).

108. A New Fluid Simulation Tool for Blender. Available online: https://80.lv/articles/a-new-fluid-simulationtool-for-blender/ (accessed on 15 May 2018).

109. Siemens Automation-Multi-Physics Simulation. Available online: https:/ /www.plm.automation.siemens. $\mathrm{com} /$ global/en/products/simulation-test/multi-physics-simulation.html (accessed on 16 May 2018).

110. Flow-3D. Available online: https:/ / www.flow3d.com/products/flow-3d/ (accessed on 16 May 2018).

111. Featool Multiphysics-Matlab. Available online: https://www.featool.com/matlab-cfd-toolbox/ (accessed on 17 May 2018).

112. NEi Software. Available online: https://www.crunchbase.com/organization/nei-software\#sectionoverview (accessed on 15 September 2018).

113. Conself. Available online: https://www.conself.com (accessed on 21 May 2018).

114. Autodesk CFD. Available online: https://www.autodesk.com/products/cfd/overview (accessed on 21 May 2018).

115. Ingrid Cloud. Available online: https:/ / www.ingridcloud.com (accessed on 21 May 2018).

116. Simright-Simulation in Your Browser. Available online: https://www.simright.com (accessed on 24 May 2018). 
117. Mantium Flow. Available online: https:/ / mantiumflow.com (accessed on 24 May 2018).

(C) 2018 by the authors. Licensee MDPI, Basel, Switzerland. This article is an open access article distributed under the terms and conditions of the Creative Commons Attribution (CC BY) license (http:/ / creativecommons.org/licenses/by/4.0/). 